\title{
Assessment of implant surface and instrument insert changes due to instrumentation with different tips for ultrasonic-driven debridement
}

\author{
Philipp Sahrmann ${ }^{*} \mathbb{0}$, Sophie Winkler, Andrea Gubler and Thomas Attin
}

\begin{abstract}
Background: To assess the changes of implant surfaces of different roughness after instrumentation with ultrasonicdriven scaler tips of different materials.

Methods: Experiments were performed on two moderately rough surfaces $\left(I-\right.$ Inicell ${ }^{\circledR}$ and $\|$-SLA $\left.{ }^{\circledR}\right)$, one surface without pre-treatment (III) and one smooth machined surface (IV). Scaler tips made of steel (A), PEEK (B), titanium (C), carbon (D) and resin (E) were used for instrumentation with a standardized pressure of $100 \mathrm{~g}$ for ten seconds and under continuous automatic motion. Each combination of scaler tip and implant surface was performed three times on 8 titanium discs. After instrumentation roughness was assessed by profilometry, morphological changes were assessed by scanning electron microscopy, and element distribution on the utmost surface by energy dispersive X-ray spectroscopy.
\end{abstract}

Results: The surface roughness of discs I and II were significantly reduced by instrumentation with all tips except E. For disc III and IV roughness was enhanced by tip A and C and, only for IV, by tip D. Instrumentation with tips B, D and E left extensive residuals on surface I, II and III. The element analysis of these deposits proved consistent with the elemental composition of the respective tip materials.

Conclusion: All ultrasonic instruments led to microscopic alterations of all types of implants surfaces assessed in the present study. The least change of implant surfaces might result from resin or carbon tips on machined surfaces.

Keywords: Dental implants, Ultrasonics, Titanium, Debridement

\section{Background}

Oral biofilms are considered the primary etiologic factor for both, periodontitis and peri-implantitis [1-3]. To disable the virulent effects of biofilms on the host organism mechanical debridement, aiming at the removal or at least destruction of the biofilm architecture, is accepted

\footnotetext{
*Correspondence: philipp.sahrmann@zzm.uzh.ch
}

Clinic of Conservative and Preventive Dentistry, Periodontology

and Cariology, Center of Dental Medicine, University of Zurich,

Plattenstrasse 11,8032 Zurich, Switzerland as a gold standard and crucial step in periodontal and peri-implant therapy $[4,5]$.

For mechanical biofilm debridement a broad range of methods and instruments are at the clinician's disposal, from simple hand scalers to electrically-driven sound and ultrasonic instruments and finally sophisticated powder abrasive devices [6-8].

Of the above, ultrasonic tips unite the major benefits of an easy usage due to electrically generated micromovements of the tips in often tight periodontal and peri-implant defects on one hand $[9,10]$ and rather low acquisition costs on the other hand. As a result these 
instruments are available in most dental practices. Therefore, they are the first choice for many clinicians when treating periodontal or peri-implant infections.

While ultrasonic instrumentation is an uncomplicated measure for periodontal defects, for the treatment of peri-implantitis, one major problem exists concerning these devices: Since titanium alloys are rather soft materials, mechanical debridement with tips of hard materials like steel or titanium have been reported to change the elaborate surface topography of the pristine implant $[11,12]$. Such changes refer to surface characteristics like roughness and hydrophilic properties, which can negatively affect healing in terms of osseo-integration when a regenerative approach is considered [13, 14] and may abet bacterial recolonization of formerly smooth surfaces [15]. Furthermore, the possible immunologic reaction to titanium particles, which are abraded from the implant by instrumentation and end up in the peri-implant tissues, is still a matter of scientific discussion [16]. Therefore, softer materials have been proposed for ultrasonic-driven tips that are used for implant surface debridement with the aim to avoid injury of the original surface morphology. Such tips, made from resin, carbon or polyether ether ketone (PEEK), have been shown to better conserve the original titanium structure [16-18]. On the other hand, these tips themselves have been reported to abrade on rough titanium surfaces and leave behind abraded tip material on the implant surface[19]. This might go along with undesired effects like quick re-colonization by biofilm or directly by triggering further inflammation in terms of foreign body reaction to the leftover residuals $[20,21]$. Since it is difficult to directly compare the potential impairing effect of either change in titanium surface morphology or the possible risk of tip residuals after debridement, a comprehensive assessment of the implant surface after instrumentation with ultrasonic tips is of relevant interest for the clinician. However, comprehensive studies involving different types of implant surfaces and a selection of the most frequently used ultrasonic tips that would be evaluated under standardized settings regarding treatment time, controlled contact pressure and standardized movements, seem to be lacking.

Therefore, the aim of the study is to conduct instrumentation under standardized settings and to assess the changes of the surface morphology in terms of roughness using contact profilometry and to detect potential residuals from tip materials by means of electron microscopic imaging. Furthermore, energy dispersive X-ray spectroscopy was used to evaluate the elementary composition on the implant surfaces before and after instrumentation.

\section{Methods}

\section{Null hypothesis}

The null-hypothesis was that the different tips would change surface roughness to the same degree without leaving tip residuals on the titanium surface.

\section{Experimental settings}

For the treatment with the ultrasonic-driven tips, the hand grip of the respective instrument was fixed in a steel holder, which allowed for vertical hinge movement (see Fig. 1). The titanium disc was placed on a flat surface and the instrument tip axis contacted the titanium surface tangentially. A constant pressure of the tip on the titanium surface of $100 \mathrm{~g}$ was set using an accuracy weighing machine (Mettler Delta Range PC 440, Mettler-Toledo, Greifensee, Switzerland) and by adjusting the position of a copper weight on the steel holder.

Instrumentation was performed on four different types of titanium discs, displaying different surface morphologies and titanium alloys.

1 Inicell implant surface (Thommen Medical, Grenchen, Switzerland).

2 SLA $^{\circledR}$ surface (Roxolid Straumann, Basel, Switzerland).

3 Surface without pretreatment (Thommen Medical, Grenchen, Switzerland).

4 Machined implant surface (Roxolid Straumann, Basel, Switzerland).

During the $10 \mathrm{~s}$ of instrumentation with fixed ultrasonic devices, discs were kept in standardized circular movement generated by an orbital shaking unit for laboratory use (IKA Vibrax VXR, IKA, Staufen, Germany) at $180 \mathrm{~Hz}$ under copious water irrigation.

Surface treatment was executed 3 times on non-overlapping areas of each disc.

On each implant surface, ultrasonic treatment was performed with the following tips: Steel (A), PEEK (B), titanium (C), carbon (D) and resin (E) (see Table 1).

Power settings of the ultrasonic devices were adjusted to the manufacturers' guidelines for the specific tips (see Table 2).

\section{Sample numbers}

Five different instrument tips driven by their corresponding ultrasonic devices were tested on 4 different kinds of titanium discs. With eight samples per tip/disc combination, a total of 160 samples were assessed, on which the instrumentation was performed threefold. 


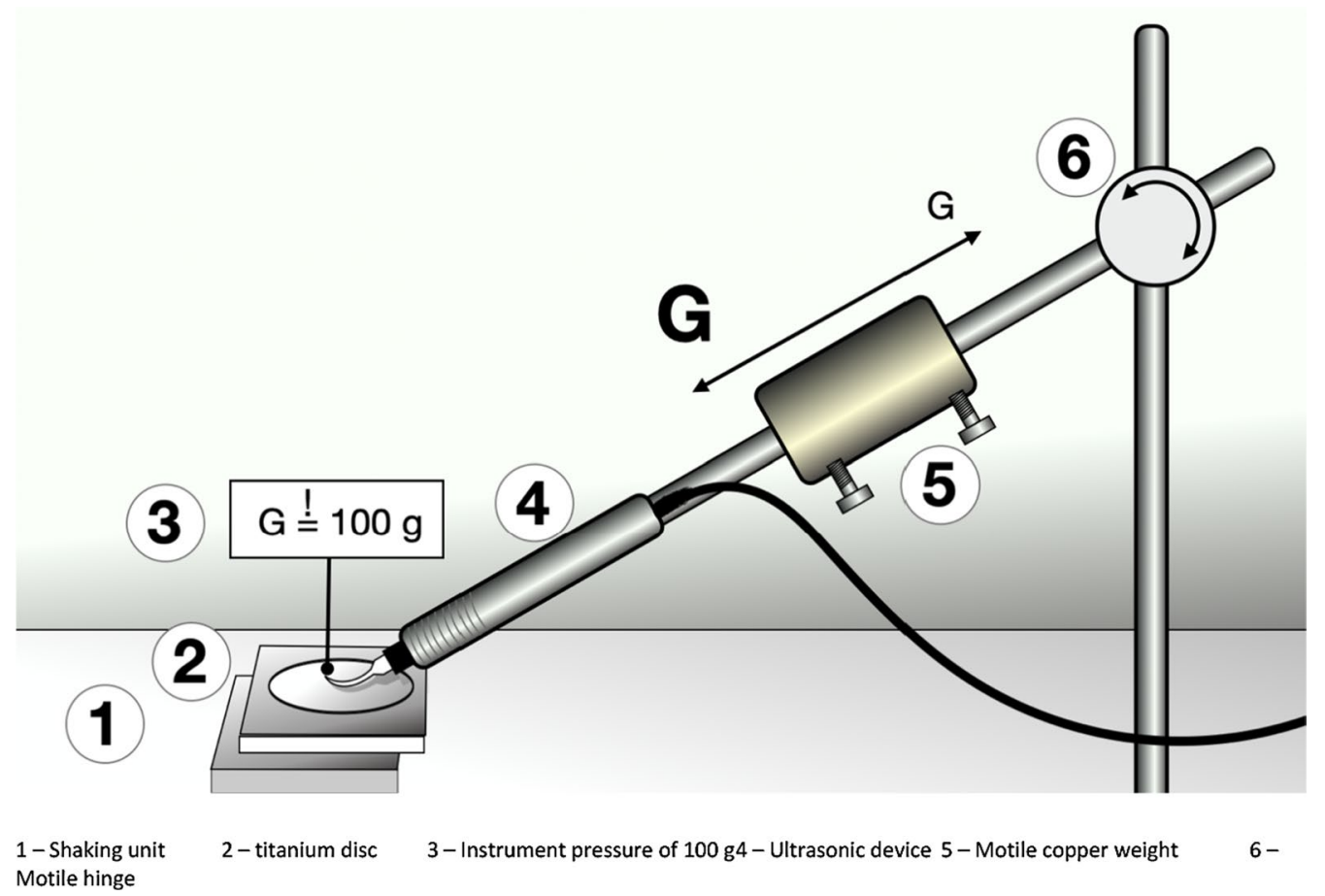

Fig. 1 Experimental set-up. 1-Shaking unit, 2-titanium disc, 3-Instrument pressure of $100 \mathrm{~g}$, 4-Ultrasonic device, 5-Motile copper weight, 6-Motile hinge

Table 1 Tips and corresponding ultrasonic devices used for the different instrumentations

\begin{tabular}{lllllll}
\hline Group & Tip & Label & Device & Manufacturer & Power setting & Tracer elements \\
\hline 0 & Controls (no instrumentation) & & & & \\
A & Steel & PL3 & miniPiezon & EMS $^{1}$ & $2 / 10$ & Fe, Cr \\
B & PEEK & PI & miniPiezon & EMS $^{1}$ & $2 / 10$ & $\mathrm{C}, \mathrm{O}$ \\
C & Titanium & IP2R & Newtron P5XS & Acteon $^{1}$ & $5 / 20$ & $\mathrm{Ti}$ \\
D & Carbon & PH1 & Newtron P5XS & Acteon & $\mathrm{C}$ \\
E & Resin & SofTip & Cavitron + Powerline & Dentsply & $2 / 20$ & $\mathrm{C}, \mathrm{O}, \mathrm{S}$ \\
\hline
\end{tabular}

${ }^{1}$ EMS SA., Nyon, Switzerland, ${ }^{2}$ Acteon (Newtron P5XS, Merignac, France), ${ }^{3}$ Dentsply professional, Pennsylvania, USA

In the column "Tracer elements" the elements detected in the respective tips by EDX are listed

\section{Profilometric analysis}

After instrumentation discs were removed from the setting without touching the instrumented surface, and the discs were dried by airflow.

The surface morphology of both, treated and untreated surfaces was then assessed using a contact profilometer (Taylor Hobson, AMETEK GmbH, Weiterstadt, Germany). On each disc, five profiles were taken on both, untreated and treated surfaces over a preset distance of $1000 \mu \mathrm{m}$. This respective assessment line was placed in a way, that the whole distance was within the homogeneously instrumented area on the disc. As for the machined surface (IV), which displayed continuous parallel grooves in the direction of pre-instrumentation, the test distances were orientated in the direction of the grooves. To characterize the surface morphology three surrogate parameters for surface roughness were assessed, of which $\mathrm{Ra}$ indicates the arithmetical mean deviation, $\mathrm{Rz}$ the maximum height of profile and Rt the range of assessed profile points of the assessed surface profile.

\section{Analysis by scanning electron microscopy (SEM)}

Scanning electron microscope images (GeminiSEM450, Carl Zeiss, Oberkochen, Germany) of the original and instrumented surfaces were generated in order to assess any change of the surface topography. 


\begin{tabular}{|c|c|c|c|}
\hline & $\mathrm{Ra}[\mu \mathrm{m}]$ & $\mathrm{Rz}[\mu \mathrm{m}]$ & Rt $[\mu \mathrm{m}]$ \\
\hline \multicolumn{4}{|l|}{ Disc I } \\
\hline $0(n=8)$ & $1.37 \pm 0.14 \mathrm{~A}$ & $7.33 \pm 0.56 \mathrm{~A}$ & $8.60 \pm 0.90 \mathrm{~A}$ \\
\hline$A(n=8)$ & $0.57 \pm 0.09 B$ & $3.40 \pm 0.61 \mathrm{~B}$ & $4.30 \pm 0.90 \mathrm{~B}$ \\
\hline$B(n=8)$ & $0.88 \pm 0.17 C$ & $4.48 \pm 0.69 C$ & $5.42 \pm 0.91 \mathrm{C}$ \\
\hline$C(n=8)$ & $0.76 \pm 0.18 \mathrm{D}$ & $4.43 \pm 0.87 C$ & $5.95 \pm 1.43 \mathrm{CD}$ \\
\hline$D(n=8)$ & $1.03 \pm 0.13 \mathrm{E}$ & $5.15 \pm 0.75 \mathrm{D}$ & $6.25 \pm 1.09 \mathrm{D}$ \\
\hline$E(n=8)$ & $1.37 \pm 0.17 \mathrm{~A}$ & $6.90 \pm 0.78 \mathrm{~A}$ & $8.27 \pm 1.03 \mathrm{~A}$ \\
\hline \multicolumn{4}{|l|}{ Disc II } \\
\hline $0(n=8)$ & $1.30 \pm 0.14 \mathrm{~A}$ & $7.33 \pm 0.82 \mathrm{~A}$ & $9.01 \pm 1.40 \mathrm{~A}$ \\
\hline$A(n=8)$ & $0.58 \pm 0.14 \mathrm{~B}$ & $3.34 \pm 0.76 \mathrm{~B}$ & $4.33 \pm 1.12 B$ \\
\hline$B(n=8)$ & $0.99 \pm 0.25 C$ & $4.03 \pm 0.83 C$ & $6.05 \pm 1.33 C$ \\
\hline$C(n=8)$ & $0.74 \pm 0.23 \mathrm{D}$ & $4.89 \pm 0.96 \mathrm{D}$ & $5.24 \pm 1.48 \mathrm{BC}$ \\
\hline$D(n=8)$ & $1.10 \pm 0.17 C$ & $5.48 \pm 0.83 C$ & $6.75 \pm 1.14 C$ \\
\hline$E(n=8)$ & $1.33 \pm 0.21 \mathrm{~A}$ & $6.94 \pm 1.22 \mathrm{~A}$ & $8.87 \pm 2.11 \mathrm{~A}$ \\
\hline \multicolumn{4}{|l|}{ Disc III } \\
\hline $0(n=8)$ & $0.40 \pm 0.07 \mathrm{~A}$ & $2.48 \pm 0.40 \mathrm{AB}$ & $3.10 \pm 0.57 \mathrm{AB}$ \\
\hline$A(n=8)$ & $0.54 \pm 0.10 \mathrm{~B}$ & $2.82 \pm 0.42 B$ & $3.47 \pm 0.69 B$ \\
\hline$B(n=8)$ & $0.39 \pm 0.07 \mathrm{~A}$ & $2.26 \pm 0.45 \mathrm{AD}$ & $2.78 \pm 0.65 \mathrm{~A}$ \\
\hline$C(n=8)$ & $0.59 \pm 0.18 \mathrm{~B}$ & $3.18 \pm 0.83 C$ & $4.44 \pm 1.31 \mathrm{C}$ \\
\hline$D(n=8)$ & $0.35 \pm 0.05 \mathrm{~A}$ & $2.04 \pm 0.30 \mathrm{D}$ & $2.55 \pm 0.46 \mathrm{~A}$ \\
\hline$E(n=8)$ & $0.37 \pm 0.04 \mathrm{~A}$ & $2.22 \pm 0.31 \mathrm{AD}$ & $2.84 \pm 0.53 \mathrm{~A}$ \\
\hline \multicolumn{4}{|l|}{ Disc IV } \\
\hline $0(n=8)$ & $0.04 \pm 0.01 \mathrm{~A}$ & $0.02 \pm 0.07 \mathrm{~A}$ & $0.26 \pm 0.08 \mathrm{~A}$ \\
\hline$A(n=8)$ & $0.42 \pm 0.08 \mathrm{~B}$ & $2.30 \pm 0.49 B$ & $2.87 \pm 0.61 \mathrm{~B}$ \\
\hline$B(n=8)$ & $0.05 \pm 0.03 \mathrm{~A}$ & $0.36 \pm 0.16 \mathrm{~A}$ & $0.45 \pm 0.18 \mathrm{~A}$ \\
\hline$C(n=8)$ & $0.36 \pm 0.18 C$ & $2.21 \pm 0.90 \mathrm{~B}$ & $3.51 \pm 1.75 \mathrm{~B}$ \\
\hline$D(n=8)$ & $0.06 \pm 0.02 \mathrm{~A}$ & $0.40 \pm 0.16 \mathrm{~A}$ & $0.53 \pm 0.30 \mathrm{~A}$ \\
\hline$E(n=8)$ & $0.04 \pm 0.02 \mathrm{~A}$ & $0.30 \pm 0.11 \mathrm{~A}$ & $0.40 \pm 0.15 \mathrm{~A}$ \\
\hline
\end{tabular}

Disc I-Inicell, Disc II—SLA, Disc III—non pretreated, Disc IV—machined 0-non instrumented surface, A-steel, B-PEEK, C-titanium, D-Carbon, E-resin

$\mathrm{Ra}$-arithmetic mean deviation of the profile

$\mathrm{Rz}$-maximum height of profile, $\mathrm{Rt}$-range of assessed profile points of the assessed surface profile

Different bold capitals indicate significant differences (valid only in the same box)

With regard to Disc 2: Roughness parameters were assessed in parallel direction to the processing direction of the machined surface

With regard to the discs, changes in the micromorphology of the original surfaces on one hand and potential residuals of the ultrasonic-driven instrument tips were assessed. With regard to the instrument tips, morphologic changes of the instruments' shape were recorded. Images were made at $15 \mathrm{kV}$ and 200pA with a working distance of $11.8-12.2 \mathrm{~mm}$ and at 500- and 10.000-fold magnification.
Analysis by energy dispersive X-ray spectroscopy (EDX)

To trace and characterize residual particles that might be left on the sample energy-dispersive X-ray spectroscopy (EDX-MaxN, Oxford instruments, High Wycombe, UK) of the tips and of treated and untreated surfaces was performed. On this behalf, discs and pristine tips were sputter-coated with a gold layer of $3.0 \mathrm{~nm}$. A mapping at a 500-fold magnification of randomly chosen areas $(100 \mu \mathrm{m} \times 100 \mu \mathrm{m})$ within the homogeneously instrumented disc for the assessment of the percental carbonium distribution was performed. For more specific analysis of potentially contaminated areas, five randomly placed scan spots along a scanning line and in a distance of $150 \mu \mathrm{m}$ from one another were placed in the area of the homogeneously instrumented discs and element analysis was performed in the point-and-id mode. The same analysis was done on untreated surface areas of the same discs, which served as controls. EDX scans on pristine ultrasonic tips were performed with the same setting like the discs, and the mean of the data from 4 measuring points in the pointand-id mode were indicated.

\section{Statistics}

For the surrogate parameters of surface roughness, mean values and standard deviations were calculated for the different groups. After checking for normal distribution of the data parametric one-way ANOVA analysis with Bonferroni correction for multiple testing was performed to assess possible intragroup differences. The level of significance was set at 0.05 . With the data of the present study, a post-hoc power analysis was performed in order to validate the samples size for the roughness assessment. Therefore, mean values and standard deviations of the different groups, the samples size were used with a significance level of 0.05 .

\section{Results}

\section{Contact profilometry}

The untreated surfaces displayed different degrees of roughness with $\mathrm{Ra}$ values varying from moderately rough with $1.37 \pm 0.14 \mu \mathrm{m}$ of disc I and $1.30 \pm 0.14 \mu \mathrm{m}$ of disc II, $0.40 \pm 0.07 \mu \mathrm{m}$ for the surface without pretreatment of disc III to finally the rather smooth machined surface with $0.04 \pm 0.01 \mu \mathrm{m}$ for disc IV.

Regarding all surrogate roughness parameters $(\mathrm{Ra}, \mathrm{Rz}$ and $\mathrm{Rt}$ ) the surfaces of disc I and II (ultra-rough) were smoothened significantly by instrumentation with all tips except the resin tip (E), which did not significantly change the surface roughness. For the surface without pre-treatment of disc III and the machined disc IV Ra was only changed by tip A (steel) and C (titanium) and, 
only for disc III, Rz was changed by tip D (carbon) (see Table 2).

\section{SEM imaging}

SEM pictures were taken to optically assess the change of the surface topography. Generally, steel and titanium tips caused a completely flattened surface and a loss of the typical morphology of the moderately rough surfaces. The same tips changed the aspect of the surface of disc III and IV, optically leaving the surface very similar to the instrumented discs I and II, thus independently from the initial disc roughness.

Treatment with peek tips slightly flattened the moderately rough surfaces while leaving minor scratches on the machined surface but none on the surface without pretreatment (III).

While disc I did not display any residual materials after instrumentation, all other surface types showed such after instrumentation with tips made from peek, carbon and resin (Table 3, Fig. 2, 3).

The power analysis showed a sufficient post-hoc power of $100 \%$.

\section{EDX assessment}

On untreated Roxolid discs (II and IV), primarily Ti (73.3-77.7\%), Zr (13-14\%), O (7-9\%) and C (3-9\%) were detected, while there were only minor contaminations by $\mathrm{S}$ and $\mathrm{Ca}$. The moderately rough surfaces and the non pretreated Thommen surface (disc I and III) showed higher amounts of $\mathrm{Ti}(75-88 \%)$, a slightly lower concentration of $\mathrm{O}(5-16 \%)$ and $\mathrm{C}(3-6 \%)$ than the respective untreated surfaces. Considerable amounts of $\mathrm{Al}$ (up to $9 \%$ and $27 \%$, respectively) were found on these surfaces, too, and spurs of $\mathrm{Ca}$ and $\mathrm{Si}$.

After instrumentation with tip B, D and E (PEEK, carbon and resin), the concentration of especially $C$ rose for the moderately rough surface and the surface without pretreatment, but did not change markedly for the machined. Likewise, element mapping images for the element carbon of both areas show higher amounts of carbon in areas instrumented with PEEK (B), carbon (D) and resin $(E)$ tips on the moderately rough surface and the one without pre-treatment, but not on the machined surface (IV). The amount and number of "foreign" elements were enhanced at the same time.

After treatment with steel tips Fe was detectable on the rough and non-pretreated Thommen surface (disc I and III) and-to a lower degree-on the machined Roxolid surface (IV), but not on the SLA surface (II) (see Table 4 and Fig. 2).

\section{Discussion}

Ultrasonic driven instruments can change the surface characteristics of titanium implants either in terms of surface roughness or in terms of residual particles from the instrument tips' material. The present study comprehensively assessed such changes induced by tips made of different materials on discs with implant surfaces of different roughness.

Table 3 Change of titanium surfaces after ultrasonic instrumentation with different tips based on SEM imaging

\begin{tabular}{|c|c|c|c|c|c|c|c|c|}
\hline \multirow{3}{*}{ Surface type } & \multirow{2}{*}{\multicolumn{2}{|c|}{ I }} & \multirow{2}{*}{\multicolumn{2}{|c|}{ II }} & \multirow{2}{*}{\multicolumn{2}{|c|}{ III }} & \multirow{2}{*}{\multicolumn{2}{|c|}{ IV }} \\
\hline & & & & & & & & \\
\hline & $\begin{array}{l}\text { Surface } \\
\text { morphology }\end{array}$ & Tip remnants & & Tip remnants & & Tip remnants & & Tipremnants \\
\hline$(n=4 \times 8)$ & $\begin{array}{l}\text { Loss of char- } \\
\text { acteristic } \\
\text { morphology, } \\
\text { flatter }\end{array}$ & None & $\begin{array}{l}\text { Loss of char- } \\
\text { acteristic } \\
\text { morphology, } \\
\text { flatter }\end{array}$ & None & $\begin{array}{l}\text { visible traces of } \\
\text { instrumenta- } \\
\text { tion, slightly } \\
\text { flatter }\end{array}$ & None & $\begin{array}{r}\text { Scratches, } \\
\text { rougher }\end{array}$ & None \\
\hline B $\quad(n=4 \times 8)$ & Slightly flatter & Sporadic & Slightly flatter & Sporadic & No changes & Sporadic & No changes & None \\
\hline$(n=4 \times 8)$ & $\begin{array}{l}\text { Loss of char- } \\
\text { acteristic } \\
\text { morphology, } \\
\text { flatter }\end{array}$ & None & $\begin{array}{l}\text { Loss of char- } \\
\text { acteristic } \\
\text { morphology, } \\
\text { flatter }\end{array}$ & None & $\begin{array}{l}\text { visible traces of } \\
\text { instrumenta- } \\
\text { tion, slightly } \\
\text { flatter }\end{array}$ & None & $\begin{array}{r}\text { Scratches, } \\
\text { rougher }\end{array}$ & None \\
\hline $\begin{array}{l}D \\
(n=4 \times 8)\end{array}$ & No changes & Sporadic & $\begin{array}{c}\text { No surface } \\
\text { changes }\end{array}$ & Slight & No changes & Slight & No changes & None \\
\hline$E^{E}(n=4 \times 8)$ & No changes & abundant & $\begin{array}{c}\text { No surface } \\
\text { changes }\end{array}$ & abundant & No changes & abundant & No changes & None \\
\hline
\end{tabular}

Disc I_Inicell, Disc II-SLA, Disc III-non pretreated, Disc IV—machined

A-steel, B-PEEK, C—titanium, D-carbon, E-resin 

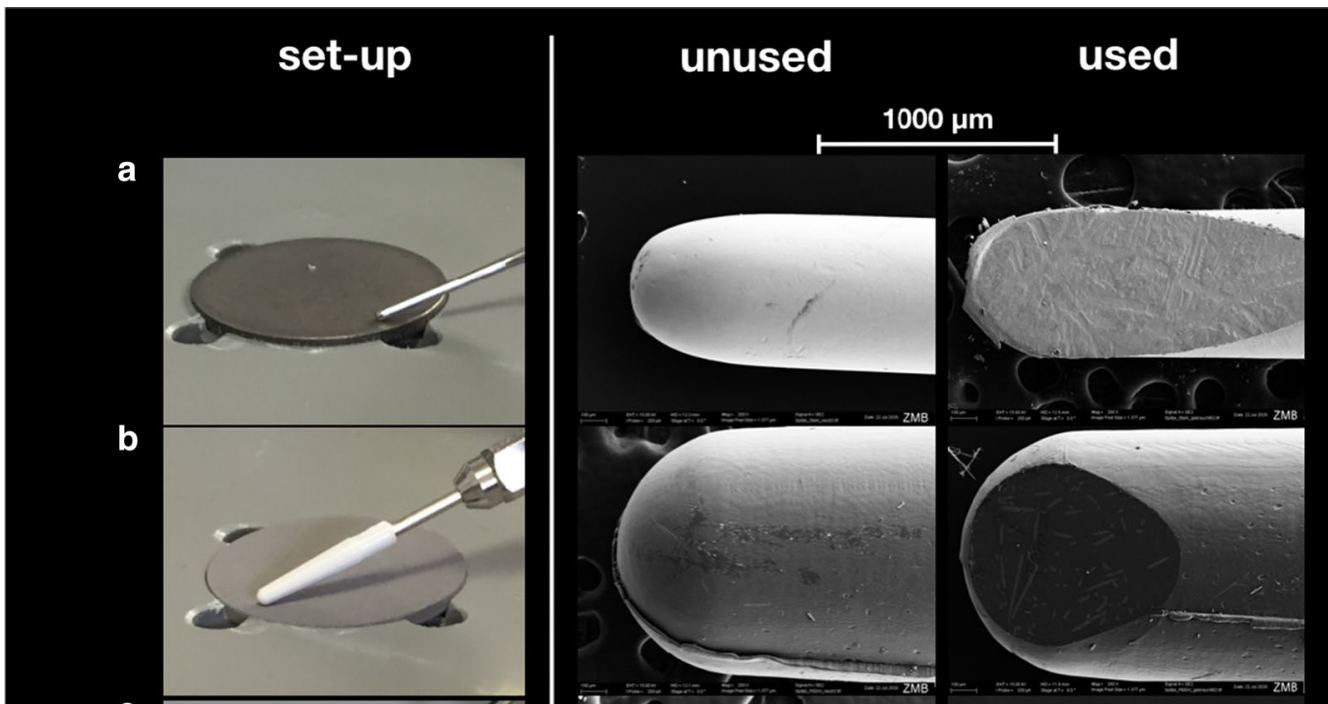

C

a

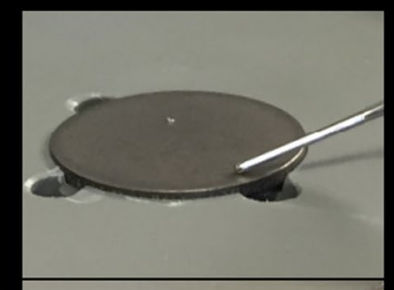

b
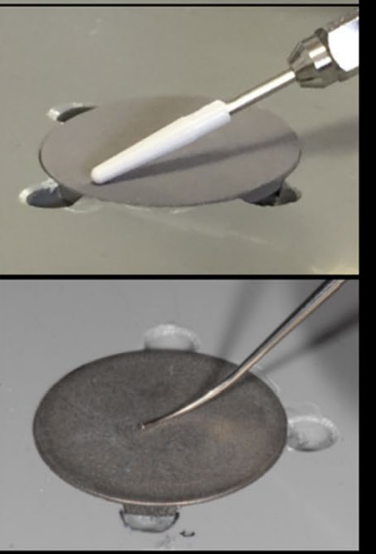

d

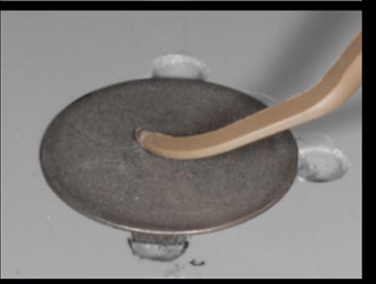

e
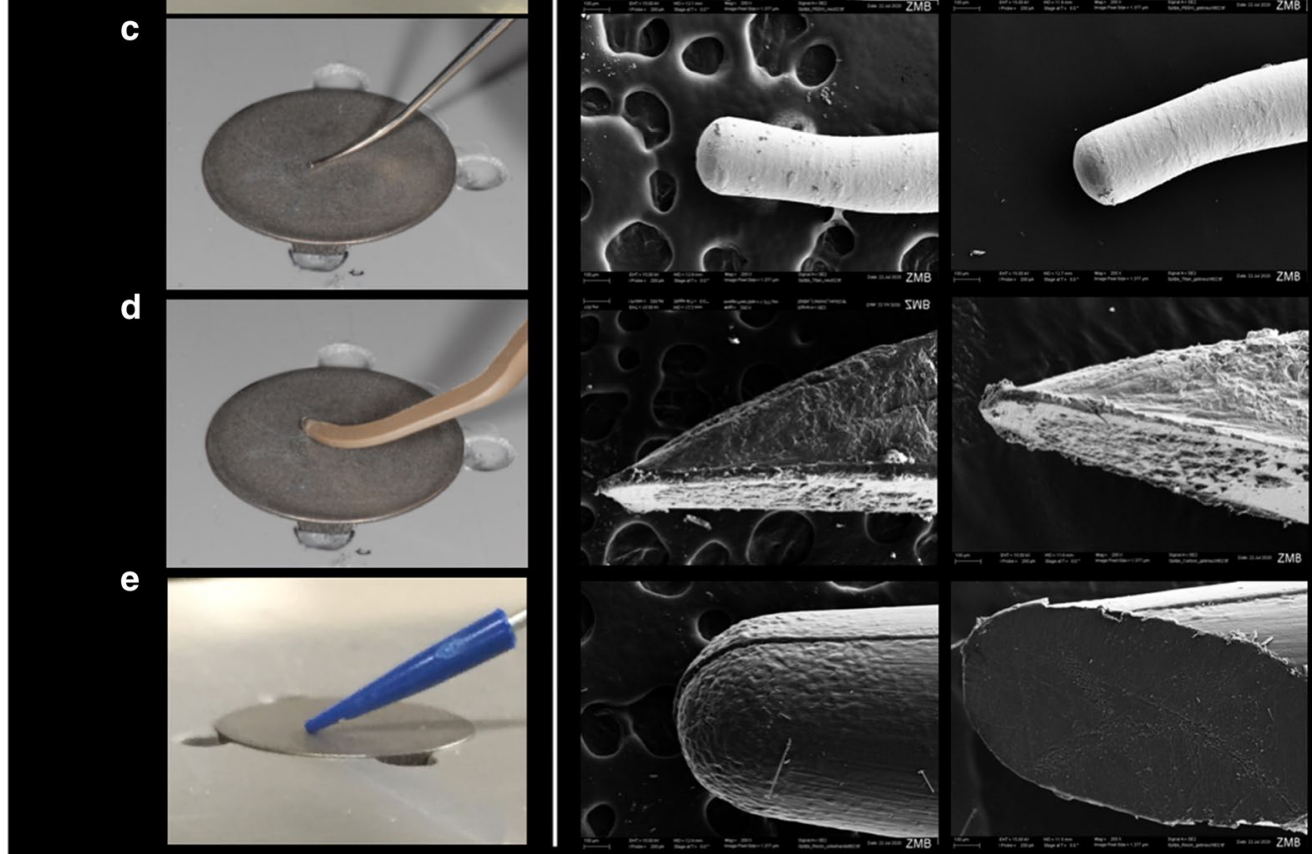

Instrument tips within the experimental set-up (left column) and at high magnification before and after instrumentation.

Fig. 2 Ultrasonic tips in the set-up, before use and after use. Instrument tips within the experimental set-up (left column) and at high magnification before and after instrumentation. a steel ("used" after $40 \times 3$ cycles), b PEEK ("used“ after $2 \times 3$ cycles), c titanium ("used" after $4 \times 4$ cycles), d carbon(„used“ after $2 \times 3$ cycles), e resin („used” after $1 \times 3$ cycles)

While tips of hard instruments like steel and titanium and-to a lower degree-PEEK changed the surface roughness in terms of a flattening of moderately rough surfaces and roughening of machined surfaces, soft tip materials like carbon, resin and-to a lower degreePEEK, tended to leave abraded material on moderately rough surfaces and the surface without pre-treatment, but not on the machined surface.
Therefore, both aspects of our null hypothesis were rejected.

Combining the findings from the different assessment methods, ie. SEM imaging and contact profilometry, both techniques indicate in accordance: Originally moderately rough surfaces, Inicell ${ }^{\circledR}$ and SLA ${ }^{\circledR}$, lost their typical surface characteristics due to the instrumentation with steel, titanium and PEEK, while the surrogate parameters Ra, 


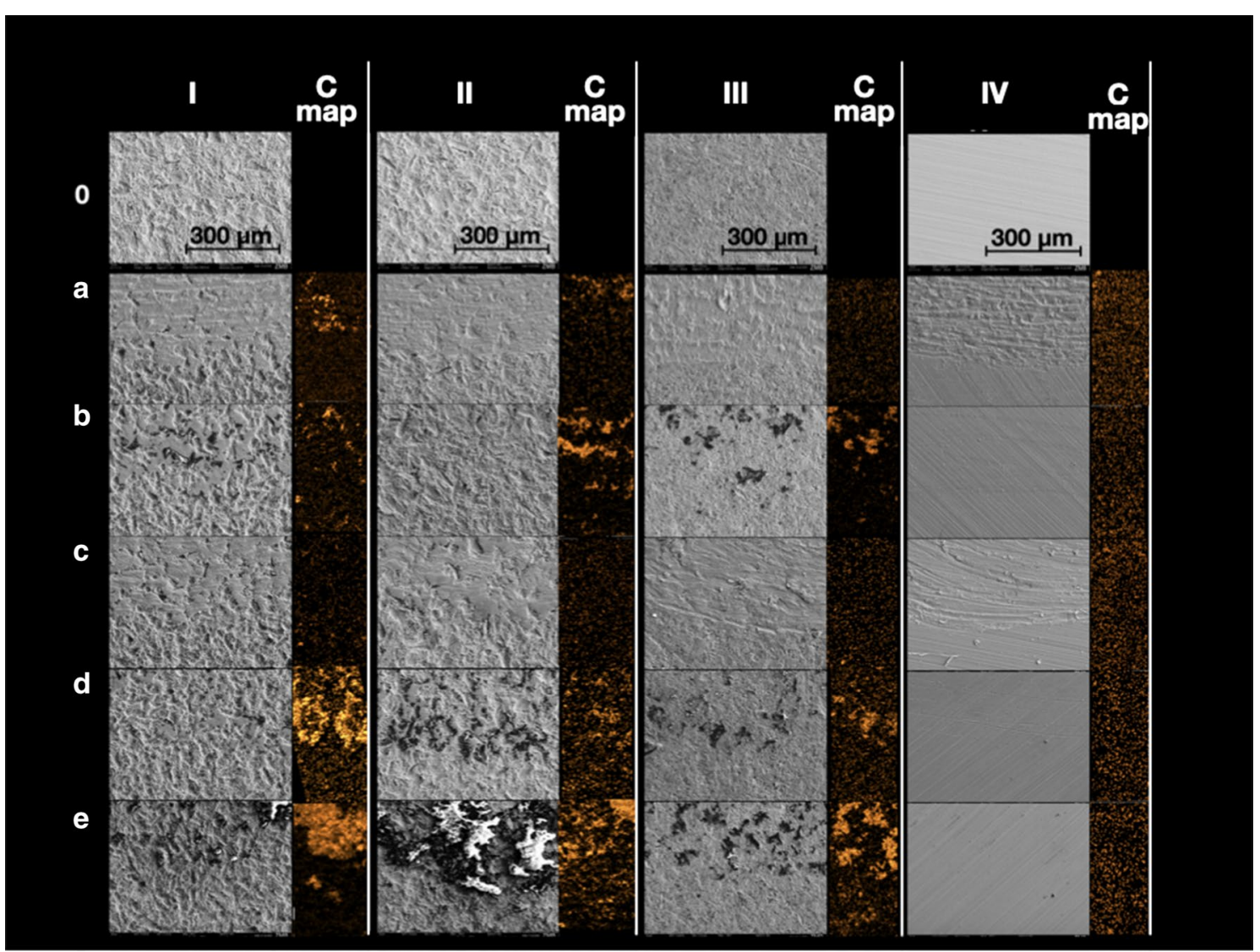

Fig. 3 Titanium surfaces after ultrasonic instrumentation with different tips. Disc I—Inicell, Disc II—SLA, Disc III—non pretreated, Disc IV— machined. C map—EDX mapping for carbon distribution on the treated (upper half) and untreated (lower half) surface areas. 0—non instrumented surface, a steel, b PEEK, c titanium, $\mathbf{d}$ carbon, e resin

$\mathrm{Rz}$ and Rt decreased significantly. On the other hand, the machined surface with a low roughness as measured in the direction of the striation caused by the machining process, reached the same roughness as the formerly moderately rough surfaces after instrumentation by the same tips. In this regard it is important to note, that the $\mathrm{Rz}$ values measured on the pristine implant surfaces are in accordance with the values published so far [22-25].

Regarding the change of roughness, the different surrogate parameters $\mathrm{Ra}, \mathrm{Rz}$ and $\mathrm{Rt}$ were generally in accordance. That means, that significant changes were found for all parameters in the same experiments, indicating that mean deviation, maximum height and the range of the profile were changed in the same way. This finding reflects that no tip left behind a surface that was characterized by especially deep scratches. The only respective exception was the change of $\mathrm{Rz}$ (but not $\mathrm{Rt}$ and $\mathrm{Ra}$ ) on the Thommen surface without pretreatment (III) after instrumentation with carbon, and the change on the machined surface (IV) treated with titanium tips for $\mathrm{Ra}$ (but not Rt and Rz). Therefore, few accented carbon particles that were detected by the contact profilometer might serve as an explanation of the above case. For the machined surface the different values for the surrogate parameters indicate an extremely homogenous-though roughened-surface after instrumentation by titanium. Whether one of the surrogate roughness parameters for surface roughness has a pronounced effect on bacterial colonization and proliferation does not emerge from today's scientific literature.

The moderately rough surface however, though not changing the surrogate parameters significantly due to instrumentation, optically displayed quite a similar appearance in the SEM images like the before-mentioned surfaces after instrumentation. These findings are in line with previous studies aiming to assess the effect of ultrasonic driven steel tips on implant surfaces [24, 25].

Likewise, the findings of the SEM images are reflected by the EDX analysis: Soft tips like PEEK, carbon and especially resin left considerable amounts of abraded material on the rough titanium surfaces. Element analysis revealed that the composition of the residuals complies 
Table 4 Volume percentage of elements originally present on the untreated surface and elements which appear after instrumentation

\begin{tabular}{|c|c|c|c|c|c|c|}
\hline $\begin{array}{l}(n=5 \text { spots } / \text { disc } \\
\text { and tip) }\end{array}$ & $\mathrm{Ti}$ & $\mathrm{Zr}$ & 0 & $C$ & fe $\%$ & te \\
\hline \multicolumn{7}{|l|}{ Disc l } \\
\hline 0 & $88.0 \pm 13.6$ & 0 & $5.4 \pm 4.8$ & $6.1 \pm 8.5$ & Al 9.9 & $\mathrm{Ca}, \mathrm{Si}$ \\
\hline A & $83.0 \pm 16.2$ & 0 & $6.4 \pm 2.1$ & $1.5 \pm 0.2$ & Fe 39.1, Cr 5.4 & - \\
\hline B & $80.7 \pm 18.3$ & 0 & $9.3 \pm 5.1$ & $9.6 \pm 15.3$ & - & $\mathrm{Al}, \mathrm{Ca}, \mathrm{Si}, \mathrm{Fe}$ \\
\hline C & $86.1 \pm 8.6$ & 0 & $10.5 \pm 5.8$ & $3.1 \pm 2.6$ & - & $\mathrm{Si}, \mathrm{Ca}$ \\
\hline $\mathrm{D}$ & $78.1 \pm 24.0$ & 0 & $18.1 \pm 20.5$ & $12.0 \pm 18.3$ & S 8, Ca 3 & - \\
\hline E & $63.1 \pm 31.7$ & 0 & $7.2 \pm 4.3$ & $27.7 \pm 26.5$ & S 6 & $\mathrm{Ca}$ \\
\hline \multicolumn{7}{|l|}{ Disc ॥ } \\
\hline 0 & $73.3 \pm 11.5$ & $12.9 \pm 2.9$ & $9.2 \pm 9.2$ & $8.7 \pm 11.1$ & - & $\mathrm{S}, \mathrm{Ca}$ \\
\hline A & $56.5 \pm 6.6$ & $12.6 \pm 0.4$ & $8.3 \pm 5.2$ & $1.9 \pm 0.7$ & - & - \\
\hline B & $71.0 \pm 15.8$ & $12.1 \pm 3.3$ & $8.1 \pm 6.3$ & $8.3 \pm 11.7$ & - & $\mathrm{Ca}, \mathrm{Al}, \mathrm{S}, \mathrm{Na}, \mathrm{Si}$ \\
\hline$C$ & $78.2 \pm 4.5$ & $13.3 \pm 0.7$ & $6.8 \pm 3.7$ & $1.7 \pm 0.9$ & - & - \\
\hline $\mathrm{D}$ & $62.3 \pm 30.9$ & $10.9 \pm 5.5$ & $6.2 \pm 2.0$ & $14.6 \pm 24.2$ & - & - \\
\hline E & $38.1 \pm 35.7$ & $6.9 \pm 6.6$ & $6.2 \pm 4.9$ & $44.2 \pm 33.6$ & S 14.0 & $\mathrm{Si}, \mathrm{Ca}$ \\
\hline \multicolumn{7}{|l|}{ Disc III } \\
\hline 0 & $74.7 \pm 16.7$ & 0 & $16.5 \pm 9.5$ & $2.7 \pm 1.5$ & $\mathrm{Al} 27$ & $\mathrm{Ca}, \mathrm{Si}$ \\
\hline A & $84.6 \pm 9.9$ & 0 & $9.0 \pm 4.0$ & $1.9 \pm 0.7$ & Fe $9.8, \mathrm{Al} 10.3$, Cr 1.5 & - \\
\hline B & $73.7 \pm 19.2$ & 0 & $10.8 \pm 4.6$ & $12.6 \pm 15.2$ & Al 9.5 & $\mathrm{Ca}, \mathrm{Si}$ \\
\hline C & $88.5 \pm 5.1$ & 0 & $8.8 \pm 4.0$ & $1.9 \pm 0.5$ & Al 5.7, & $\mathrm{Si}$ \\
\hline$D$ & $58.1 \pm 17.7$ & 0 & $19.4 \pm 10.3$ & $12.8 \pm 15.9$ & S 13, Ca 12, Al 5, Si 2.0 & - \\
\hline E & $44.2 \pm 35.4$ & 0 & $17.9 \pm 10.5$ & $21.4 \pm 23.3$ & Al 51, S 6 & $\mathrm{Ca}, \mathrm{Na}, \mathrm{Si}$ \\
\hline \multicolumn{7}{|l|}{ Disc IV } \\
\hline 0 & $77.7 \pm 2.7$ & $13.9 \pm 1.9$ & $7.1 \pm 10.2$ & $3.3 \pm 1.4$ & - & - \\
\hline A & $78.8 \pm 5.3$ & $12.3 \pm 2.2$ & $6.0 \pm 3.7$ & $1.7 \pm 1.6$ & Fe 3.2 & - \\
\hline B & $79.4 \pm 2.2$ & $12.9 \pm 0.8$ & $5.4 \pm 2.1$ & $2.3 \pm 0.5$ & - & - \\
\hline C & $77.0 \pm 4.9$ & $14.5 \pm 2.8$ & $5.2 \pm 1.7$ & $3.1 \pm 1.6$ & - & $\mathrm{Fe}, \mathrm{Ca}$ \\
\hline$D$ & $77.4 \pm 3.5$ & $12.9 \pm 1.2$ & $7.3 \pm 3.3$ & $2.4 \pm 1.0$ & - & - \\
\hline E & $73.0 \pm 13.4$ & $35.0 \pm 44.2$ & $3.9 \pm 0.5$ & $7.6 \pm 9.7$ & - & $\mathrm{Ca}, \mathrm{S}, \mathrm{B}$ \\
\hline
\end{tabular}

Disc I-Inicell, Disc II—SLA, Disc III—non pretreated, Disc IV—machined

0 -non instrumented surface, A-steel, B-PEEK, C-titanium, D-Carbon, E-resin

Ti-Titanium, $\mathrm{Zr}$-zirconium, $\mathrm{O}$ - oxygen, $\mathrm{C}$-carbon, fe-foreign metals $>1.0 \%$, te-traces of foreign elements

with the respective tip materials, which were assessed in a pre-study EDX assessment (see Table 1, right column). High levels of $\mathrm{Al}$ on the pristine Thommen surfaces might be explainable due to the packaging, since the discs were shipped wrapped in aluminum foil. As only the special test discs but not the screw-shaped implants for clinical use are packed in aluminum this issue is without any clinical impact.

Since the aim of the study was the simulation of the clinical situation, instrument settings regarding the intensity ("power settings") were adjusted according to the manufacturers' guidelines. Thus, the analysis regarding roughness surrogate parameters, optical assessment of the tips and SEM imaging and EDX analysis do not allow for a direct comparison of the single experiments, i.e. discs and tip materials. However, the outcomes reflect a comparison of the potential changes caused by different systems in the way they are clinically used for implant debridement. Even though the absolute pressure was accurately set to $100 \mathrm{~g}$ before the experiment started, differences regarding the relative pressure of the tip on the titanium surface must be considered for two reasons: First, since the different tips differ in size of the pristine tips. Also, tips of soft materials abraded much more which would have quickly resulted in a greater contact area between tip and implant surface. Both observations have a direct impact on the relative contact pressure though the total load on the tips was standardized.

To estimate and compare possible negative effects of either changed surface roughness or remnants from 
tip material is difficult, since corresponding data from clinical studies are still missing. Changing moderately rough surfaces means to drive down the surface wettability and-contemporaneously-the biocompatibility of the surfaces [26-28]. Which means a decisive disadvantage for bone healing, however, may be an advantage if surfaces remain exposed to the oral flora, where smoother surfaces are less prone to biofilm adhesion [29-31]. Of course, the same principle is valid for the opposite: Roughening rather smooth surfaces like machined surfaces might facilitate biofilm adhesion. Since this kind of surface is used in the implants' neck area, this issue is of special importance: Treating the area close to the so-called emergence profile with ultrasonic tips of hard materials such as steel or titanium might therefor abet the occurrence of mucositis as a direct reaction of biofilm accumulation. Moreover, particles of the titanium surface, which are displaced into the adjacent peri-implant mucosa by instrumentation with tips from hard materials have been reported to have detrimental effects on the surrounding tissues. On one hand, detached titanium particles have been shown to have a significant direct effect on the inflammatory response, thereby inducing peri-implant osteolysis and macrophage response. [32-34] On the other hand, these particles favor a noxious shift in the adjacent biofilm [35].

Using soft tip materials, considerable amounts of debris were found on the rough implant surfaces. According to the EDX analysis, the elemental composition of these coincides with the material of the respective tips. Though so far no impairing effect of such residuals has been clinically proven and the material itself is not toxic, a concept that would replace biofilm contamination by remnants from foreign material on the surface is not plausible. The smooth implant surfaces, however, were less affected by residual particles. Therefore, the use of such tips made from softer materials like resin or carbon on machined areas-typically located at the implants' neck-seems rather unproblematic.

Taken together, the results indicate that ultrasonic debridement of titanium surfaces is strongly limited in terms of either changes of the surface morphology or residuals from the ultrasonic tips. Therefore, alternatively non-contact approaches like the use of non-abrasive powders in powder abrasive devices [36] or diode lasers [37] might be beneficial [38]. The latter might also better overcome the problem of surface areas that remain inaccessible to ultrasonic tips, like areas under the windings of screw-shaped implants $[12,39,40]$.

Translating the meaning of findings of the present invitro study for the clinical situation, some limitations of the present design have to be considered:
First, no screw-shaped implants but discs with the respective surfaces have been used in order to standardize both instrumentation and assessment of the surfaces. Cylindrical implant geometry and threads however constitute surface features that might change the assumptions with regard to homogeneous flattening and abrasion considerably. Then, the present study provides no data regarding whether and to which extent biofilm removal from the surfaces is possible with the respective ultrasonic driven tips. Previous studies, however, showed that biofilm removal is basically possible with ultrasonic tips [41] and that ultrasonic debridement may be part of a clinically successful mucositis treatment [42]. Ronay et al. revealed, however, in a series of vitro-studies that ultrasonic debridement even with steel tips is heavily limited especially in tight peri-implant defects on one hand and in the area under the threads of screw-shaped implants on the other hand $[39,40]$. Furthermore it should be considered that biofilm colonization itself might influence the abrasion process on the rough surfaces.

Surface planimetric assessment was performed by a profilometer, which works two-dimensionally. Since the titanium discs themselves were flat and the instrumentation was performed in circular movements, this categorical limitation might not have had a major effect on the results.

Another limitation of the present study is the settings of the EDX assessment. Element analysis was not performed over the entire treated area. The respective scan would have needed weeks of processing time with the device used in the current experiment. Instead, EDX was performed in 5 measuring points on each instrumented and pristine implant surface. The analysis does therefore not depict a "true" distribution of the mean of different elements' volume percentage on the surface, but an estimate based on numerous spots that were-however-determined by a standardized protocol. This is the reason why the EDX results were not tested for significant differences.

\section{Conclusions}

Hard tip materials like steel and titanium change the surface roughness of rough titanium surfaces while softer tip materials like carbon or resin abrade on rough surfaces. PEEK tips displayed both disadvantages but less pronounced than the other materials. Accordingly, and within the limitations of this in-vitro assessment in mind, the least change on implant surfaces might result from resin or carbon tips on machined surfaces.

\section{Abbreviations}

C: carbon; Ca: calcium; EDX: energy dispersive X-ray spectroscopy; fe: foreign metals; kV: kilo Volt; O: oxygene; pA: pico Ampere; PEEK: 
polyether etherketone; Ra: arithmetical mean deviation of the profile; Rz: maximum height of the profile; Rz: the range of assessed profile points; SEM: scanning electron microscopy; te: traces of foreign elements; Ti: titanium; $Z$ r: zirconium.

\section{Acknowledgements}

The authors thank Claudia Cucuzza for her continuous support during instrumentation and assessment of the samples.

\section{Authors' contributions}

PS worked out the conceptual design, supervised the experiments and wrote the text. SW performed the experiments and the assessment of the surface roughness and helped with writing. BG supervised the experiments, performed the SEM and EDX analysis and revised the text. TA helped with conceptualization and revised the text. All authors have read and approved the manuscript.

\section{Funding}

Implant discs with different roughness were provided by Straumann AG (Basel, Switzerland) and Thommen Medical (Grenchen, Switzerland). Instrument tips were provided by Acteon (Merignac Cedex, France) and EMS S.A. (Nyon, Switzerland). The funders had no influence on design, methods, results and the discussion section of the manuscript.

\section{Availability of data and materials}

The datasets used and/or analysed during the current study are available from the corresponding author on reasonable request.

\section{Consent for publication}

Not applicable.

Ethics approval and consent to participate

Not applicable for the present in-vitro study.

\section{Competing interests}

The authors declare that they have no competing interests.

Received: 8 September 2020 Accepted: 23 December 2020

Published online: 07 January 2021

\section{References}

1. Sanz M. Teughels Working Group AOEWOP: Innovations in non-surgical periodontal therapy: Consensus Report of the Sixth European Workshop on Periodontology. J Clin Periodontol. 2008;35(8 Suppl):3-7.

2. Takizawa S, Watanabe H, Naito Y, Inoue S. Preparative action of carbon tetrachloride in liver tumorigenesis by a single application of N-butylnitrosourea in male ICR/JCL strain mice. Gan. 1975;66(6):603-14.

3. Pérez-Chaparro PJ, Duarte PM, Shibli JA, Montenegro S, Lacerda Heluy S, Figueiredo LC, Faveri M, Feres M. The current weight of evidence of the microbiologic profile associated with peri-implantitis: a systematic review. J Periodontol. 2016;87(11):1295-304.

4. Renvert S, Polyzois I: Treatment of pathologic peri-implant pockets. Periodontol 2000 2018, 76(1):180-190.

5. Aimetti M. Nonsurgical periodontal treatment. Int J Esthet Dent. 2014;9(2):251-67.

6. Slots J: Periodontitis: facts, fallacies and the future. Periodontol 20002017 , 75(1):7-23.

7. Guentsch A, Preshaw PM. The use of a linear oscillating device in periodontal treatment: a review. J Clin Periodontol. 2008;35(6):514-24.

8. Petersilka GJ: Subgingival air-polishing in the treatment of periodontal biofilm infections. Periodontol 2000 2011, 55(1):124-142.

9. Kawashima H, Sato S, Kishida M, Ito K. A comparison of root surface instrumentation using two piezoelectric ultrasonic scalers and a hand scaler in vivo. J Periodontal Res. 2007;42(1):90-5.

10. Drisko CL, Cochran DL, Blieden T, Bouwsma OJ, Cohen RE, Damoulis P, Fine JB, Greenstein G, Hinrichs J, Somerman MJ, lacono V, Genco RJ, Research SATCOTAAOP: Position paper: sonic and ultrasonic scalers in periodontics. Research, Science and Therapy Committee of the American Academy of Periodontology. J Periodontol 2000, 71(11):1792-1801.
11. Fox SC, Moriarty JD, Kusy RP. The effects of scaling a titanium implant surface with metal and plastic instruments: an in vitro study. J Periodontol. 1990;61 (8):485-90.

12. Sahrmann $P$, Ronay $V$, Hofer $D$, Attin $T$, Jung RE, Schmidlin PR. In vitro cleaning potential of three different implant debridement methods. Clin Oral Implants Res. 2015;26(3):314-9.

13. Smeets R, Stadlinger B, Schwarz F, Beck-Broichsitter B, Jung O, Precht C, Kloss F, Gröbe A. Heiland M. Ebker T: Impact of dental implant surface modifications on osseointegration. Biomed Res Int; 2016. p. 20166285620.

14. Sedlaczek J, Lohmann CH, Lotz EM, Hyzy SL, Boyan BD, Schwartz Z. Effects of low-frequency ultrasound treatment of titanium surface roughness on osteoblast phenotype and maturation. Clin Oral Implants Res. 2017;28(10):e151-8.

15. Teughels W, Van Assche N, Sliepen I, Quirynen M. Effect of material characteristics and/or surface topography on biofilm development. Clin Oral Implants Res. 2006;17(Suppl 2):68-81.

16. Trindade R, Albrektsson T, Tengvall P, Wennerberg A. Foreign body reaction to biomaterials: on mechanisms for buildup and breakdown of osseointegration. Clin Implant Dent Relat Res. 2016;18(1):192-203.

17. Sato S, Kishida M, Ito K. The comparative effect of ultrasonic scalers on titanium surfaces: an in vitro study. J Periodontol. 2004;75(9):1269-73.

18. Huang YS, Hung CY, Huang HH. Surface changes and bacterial adhesion on implant abutment materials after various clinical cleaning procedures. J Chin Med Assoc. 2019;82(8):643-50.

19. Schmage P, Kahili F, Nergiz I, Scorziello TM, Platzer U, Pfeiffer P. Cleaning effectiveness of implant prophylaxis instruments. Int J Oral Maxillofac Implants. 2014;29(2):331-7.

20. Brookshire FV, Nagy WW, Dhuru VB, Ziebert GJ, Chada S. The qualitative effects of various types of hygiene instrumentation on commercially pure titanium and titanium alloy implant abutments: an in vitro and scanning electron microscope study. J Prosthet Dent. 1997;78(3):286-94.

21. Harrel SK, Wilson TG, Pandya M, Diekwisch TGH. Titanium particles generated during ultrasonic scaling of implants. J Periodontol. 2019;90(3):241-6.

22. Wolter D: Biocompatibility of carbon fibre and carbon fibre microparticles. Aktuelle Probl Chir Orthop 1983, 2628-36.

23. Lossdörfer S, Schwartz Z, Wang L, Lohmann CH, Turner JD, Wieland M, Cochran DL, Boyan BD. Microrough implant surface topographies increase osteogenesis by reducing osteoclast formation and activity. J Biomed Mater Res A. 2004;70(3):361-9.

24. Unursaikhan O, Lee JS, Cha JK, Park JC, Jung UW, Kim CS, Cho KS, Choi SH. Comparative evaluation of roughness of titanium surfaces treated by different hygiene instruments. J Periodontal Implant Sci. 2012;42(3):88-94.

25. Ramaglia L, di Lauro AE, Morgese F, Squillace A. Profilometric and standard error of the mean analysis of rough implant surfaces treated with different instrumentations. Implant Dent. 2006;15(1):77-82.

26. Schwartz Z, Boyan BD. Underlying mechanisms at the bone-biomaterial interface. J Cell Biochem. 1994;56(3):340-7.

27. Raines AL, Olivares-Navarrete R, Wieland M, Cochran DL, Schwartz $Z$, Boyan BD. Regulation of angiogenesis during osseointegration by titanium surface microstructure and energy. Biomaterials. 2010;31(18):4909-17.

28. Montero J, Fernández-Ruiz A, Pardal-Peláez B, Jiménez-Guerra A, VelascoOrtega E, Nicolás-Silvente Al, Monsalve-Guil L. Effect of rough surface platforms on the mucosal attachment and the marginal bone loss of implants: a dog study. Materials (Basel). 2020;13(3):802.

29. Jin SH, Lee EM, Park JB, Kim KK, Ko Y. Decontamination methods to restore the biocompatibility of contaminated titanium surfaces. J Periodontal Implant Sci. 2019;49(3):193-204.

30. Azzola F, lonescu AC, Ottobelli M, Cavalli N, Brambilla E, Corbella S, Francetti L. Biofilm formation on dental implant surface treated by implantoplasty: an in situ study. Dent J (Basel). 2020;8(2):40.

31. Lee BS, Shih KS, Lai CH, Takeuchi Y, Chen YW. Surface property alterations and osteoblast attachment to contaminated titanium surfaces after different surface treatments: an in vitro study. Clin Implant Dent Relat Res. 2018;20(4):583-91.

32. Eger M, Sterer N, Liron T, Kohavi D, Gabet Y. Scaling of titanium implants entrains inflammation-induced osteolysis. Sci Rep. 2017;7:39612.

33. Kotsakis GA, Black R, Kum J, Berbel L, Sadr A, Karoussis I, Simopoulou M, Daubert D: Effect of implant cleaning on titanium particle dissolution and cytocompatibility. J Periodontol 2020 (online ahead of print). 
34. Ingham E, Fisher J. The role of macrophages in osteolysis of total joint replacement. Biomaterials. 2005;26(11):1271-86.

35. Souza JGS, Costa Oliveira BE, Bertolini M, Lima CV, Retamal-Valdes B, de Faveri M, Feres M, Barão VAR. Titanium particles and ions favor dysbiosis in oral biofilms. J Periodontal Res. 2020;55(2):258-66.

36. Schwarz F, Becker K, Bastendorf KD, Cardaropoli D, Chatfield C, Dunn I, Fletcher P, Einwag J, Louropoulou A, Mombelli A, Ower P, Pavlovic P, Sahrmann P, Salvi GE, Schmage P, Takeuchi Y, Van Der Weijden F, Renvert S. Recommendations on the clinical application of air polishing for the management of peri-implant mucositis and peri-implantitis. Quintessence Int. 2016;47(4):293-6.

37. Mattar H, Bahgat M, Ezzat A, Bahaa El-Din B, Keraa K, El Taftazany I. Management of peri-implantitis using a diode laser $(810 \mathrm{~nm})$ vs conventional treatment: a systematic review. Lasers Med Sci. 2020.

38. Wang CW, Renvert S, Wang HL. Nonsurgical treatment of periimplantitis. Implant Dent. 2019;28(2):155-60.

39. Ronay V, Merlini A, Attin T, Schmidlin PR, Sahrmann P (2017) In vitro cleaning potential of three implant debridement methods. Simulation of the non-surgical approach. Clin Oral Implants Res 28(2):151-155.
40. Steiger-Ronay V, Merlini A, Wiedemeier DB, Schmidlin PR, Attin T, Sahrmann P. Location of unaccessible implant surface areas during debridement in simulated peri-implantitis therapy. BMC Oral Health. 2017;17(1):137

41. Otsuki M, Wada M, Yamaguchi M, Kawabata S, Maeda Y, Ikebe K. Evaluation of decontamination methods of oral biofilms formed on screwshaped, rough and machined surface implants: an ex vivo study. Int J Implant Dent. 2020;6(1):18.

42. Blasi A, lorio-Siciliano V, Pacenza C, Pomingi F, Matarasso S, Rasperini G. Biofilm removal from implants supported restoration using different instruments: a 6-month comparative multicenter clinical study. Clin Oral Implants Res. 2016;27(2):e68-73.

\section{Publisher's Note}

Springer Nature remains neutral with regard to jurisdictional claims in published maps and institutional affiliations.
Ready to submit your research? Choose BMC and benefit from:

- fast, convenient online submission

- thorough peer review by experienced researchers in your field

- rapid publication on acceptance

- support for research data, including large and complex data types

- gold Open Access which fosters wider collaboration and increased citations

- maximum visibility for your research: over $100 \mathrm{M}$ website views per year

At BMC, research is always in progress.

Learn more biomedcentral.com/submissions 